\title{
The Enduring Concepts of Carolyn Kenny
}

\author{
Kenneth E. Bruscia * \\ *kbruscia@gvtc.com \\ Received: 31 June 2018 Accepted: 24 September 2018 Published: 15 October 2018 \\ Editor: Katrina McFerran Reviewer: Brynjulf Stige
}

Carolyn Kenny devoted much of her career to the development of music therapy theory. Her method can be described as a "reflective synthesis" of knowledge and practice in music therapy and related disciplines, and of her own personal experiences with clients.

My approach to the task at hand is reflective. My scholarship has informed me, but no more than my direct experience with clients. I have been influenced by powerful thoughts of eloquent scholars. I have attempted to finely tune my ability to discern categories. I have studied the major intellectual influences of our time and the historical contexts of movements of thought. I release them all. I surrender my thoughts to Debbie, Jack, Robyn, Maggie, Mable and many other patients and client in my clinical work life.

In her first book, The Mythic Artery, Kenny (1982) began her theoretical journey by making connections between music, myth, and nature, showing how the death-rebirth cycle is inherent in them all. In interweaving these elements with the healing properties of music, Kenny identified constructs that continued to evolve in her later writings. She began to explore the roles of symbolism, ritual, creativity, paradox, archetypal patterns, rhythms of life, and tension-resolution cycle.

These new constructs necessitated an even larger sphere for music therapy than those explored in The Mythic Artery. Three years later, she began to consider exploring the relevance of systems theory. As a discipline of disciplines, systems theory helped Kenny to place her theoretical ideas in larger and larger frames, with endless and overlapping boundaries. In its concern for wholeness, and the interplay and connectedness of all parts, systems theory provided a way to harmonize art, science, and spirituality, and thereby apprehend the state of wholeness found in the universe. Kenny then proposed that the whole system is made up of different "fields" within fields, and "spaces" within the fields, where the quest for wholeness (healing) unfolds and is re-enacted through their dynamic interplay. These notions then provided the foundation for examining how music is a model of the whole system, as well as a field and space within the system. Implicit is the idea that music is a vehicle to wholeness and healing-it provides the opportunity for creativity and ritual that can reconnect us to the harmony of the universe.

The Field of Play (1989) can be seen as the culmination of many of Kenny's previous ideas, as well as the beginning of a newly organized direction for her theorizing. So far, she had identified the regenerative experience as a core process in music and nature, with wholeness and healing as the ultimate quest; and through her lens of systems theory, she had begun to identify many of the interdependent elements, fields, and spaces that interact in the ongoing process of re-connecting to this quest. Now, she was to organize these ideas into a formal theory and find a language that was closer to her 
understanding of the music therapy process. The Field of Play also introduced a two core constructs for the entire system-love and the creation of beauty.

The value of a loving and supportive field which has its goal the creation of beauty seems to me a simple human idea which is clear and unequivocal for any type of development, therapeutic or otherwise (1989, p. 7).

This loving and supportive field is the source from which all other fields in the system unfold, and in music therapy, it unfolds in sound. Briefly, Kenny's field of play theory proposed that there are seven fields essential to music therapy.

1. The aesthetic: a field or environment containing the conditions of beauty, including the human being. This is the loving and supportive field that resources all others.

2. The musical space: the contained space that arises out of the aesthetic when therapist and client relate to one another through music.

3. The field of play: the open field that arises out of the aesthetic field and the musical space, and which expands into a field of experimentation, play, and modeling. The field of play contains four interactive fields, as follows:

4. Ritual: any repeatable form created through the conditions present at the time.

5. A particular state of consciousness: a field of relaxation, concentration, and playfulness.

6. Power: the field of energy that motivates receptivity and induces action

7. Creative Process: the process and field that results from the interplay and overlaps of the previous fields.

These fields are environments that have varying conditions, and which operate in an organic ecology according to certain principles. When the fields overlap, or when elements or conditions interact, a relationship emerges, and a new field is created.

Because Kenny had been building a general theory of music therapy, not tied to specific methods or populations, her constructs were quite broad, and she carefully avoided defining or classifying the various fields and conditions in a way that that would violate their characteristic openness. Nevertheless, in a continuing attempt to communicate her theory, Kenny (1996) began to describe the fields of play in terms of their intrinsic qualities.

I have identified specific qualities which are characteristic of each of the seven fields. They may be characteristic. But they do not allow me to "operationalize" the fields. However, they do allow me to say something to my colleagues about how I recognize the fields, how they distinguish themselves from each other. For example, in the "aesthetic," an important quality of the field is anticipation. In "the musical space," intimacy is a central quality; in the "field of play" surprise, in "ritual," repetition; in "a particular state of consciousness," suspendedness or flight; in "power," intensity; in "the creative process," epiphany or awakening. There are many more. These qualities serve as guide posts (1996, p. 94).

In a subsequent publication (Kenny, 1999) identified the many challenges inherent in developing a general theory of music therapy and suggested to other theorists that there are key topics that must be addressed, including aesthetics, intersubjectivity, empathy, uniqueness, and the representation of our experiences through symbols, analogies, and metaphors.

Throughout these years of theorizing, Kenny often reminded herself of her own indigenous roots. Her mother was a Choctaw American Indian. These roots enabled Kenny to call upon the wisdom of the Native world to inform and enlarge her ways of thinking about music therapy. She also continued to "return home", that is, to focus her talents and skills to bettering the lives of peoples in her own culture and her own community. In carrying out this work, she rediscovered the centrality of spirit, play, art and healing in indigenous or "first nation" peoples (Kenny, 2004). 
Finally, Kenny (1998) was also committed to bringing greater coherence to her contemporary and indigenous ideas and developing ways to integrate them into current practice, research, and education in music therapy. Of key concern was the need to embrace diversity and the complexities that accompany it.

Kenny was bold and brave-personally and professionally. She approached the task of theorizing with awe while also recognizing that we must not be daunted by the intricacies of our personal, cultural, and professional worlds. She taught us that we must honor their vastness and elusiveness, while also daring to describe them in ways that bring a better understanding of life, as both human and spirit.

She left us too soon, but her concepts will endure. As a colleague and friend, I will greatly miss her daring.

\section{References}

Kenny, C. (1982). The mythic artery: The magic of music therapy. Atascadero, CA: Ridgeview Publishing.

Kenny, C. (1985). Music: A whole systems approach. Music Therapy: Journal of the American Association for Music therapy, 5(1), 3-11.

Kenny, C. (1989). The field of play: A guide for theory and practice in music therapy. Atascadero, CA: Ridgeview Publishing.

Kenny, C. (1996). The dilemma of uniqueness: An essay on consciousness and qualities. Nordic Journal of Music Therapy, 5(2), 87-96.

Kenny, C. (1998). Embracing complexity: The creation of a comprehensive research culture in music therapy. Journal of Music Therapy, 35(3), 201-217.

Kenny, C. (1999). Beyond this point there be dragons: Developing concepts for general theory in music therapy. Nordic Journal of Music Therapy, 9(2), 127-136.

Kenny, C. (2004). Introduction. In Music and life in the field of play: An anthology (pp. 147-148). Dallas, TX: Barcelona Publishers. 